\title{
UMA INVESTIGAÇÃO SOBRE O PROCESSO DE MENSURAÇÃO DE ÍNDICES DE EFICIÊNCIA TÉCNICA EM DISTRIBUIDORAS DE ENERGIA ELÉTRICA NO BRASIL
}

\section{Diego Dorneles Goulart}

Professor Substituto da Universidade Federal do Pampa.

Endereço para contato: Rua Barão do Triunfo, 1048. Centro Ï Santana do Livramento - RS

CEP: 97573-634 ï E-mail: diego.goulart1976@gmail.com

\author{
Maurício Sperandio \\ Professor Adjunto da Universidade Federal de Santa Maria e da Universidade Federal do Pampa. \\ Endereço para contato: Avenida Roraima no 1000. Cidade Universitária - Centro de Tecnologia, Prédio 10. Sala \\ 524. Camobi ï Santa Maria - RS. \\ CEP. 97015-900 ï E-mail: sperandio.m@gmail.com
}

Recebido em 18 de fevereiro de 2016. Aceito em 13 de maio de 2016.

\section{RESUMO}

Neste artigo investiga-se o processo de mensuração dos índices de eficiência técnica para as 30 maiores empresas distribuidoras de energia elétrica no Brasil. Assim, confronta-se a metodologia da Agência Nacional de Energia Elétrica (ANEEL) para a avaliação dos custos operacionais regulatórios do ciclo de revisão tarifária periódica frente à metodologia alternativa proposta para observar o desempenho de eficiência técnica destas empresas associando aspectos de qualidade dos serviços prestados à sociedade. Para tanto, foi utilizada a Data Envelopment Analysis ï DEA (com modelos DEA orientados para insumo). Foram adotados dois cenários: no $\mathrm{C} 1$, observam-se as variáveis quantitativas adotadas pela ANEEL, e no $\mathrm{C} 2$, inserem-se variáveis de qualidade de serviço. Desta forma, com base nos resultados de desempenho relativo para o período analisado identificam-se medidas de eficiência técnica com tendência de evolução positiva, para o conjunto das 30 maiores empresas distribuidoras de energia elétrica. Por fim, são expostas algumas considerações sobre a necessidade de aprimorar alguns pontos na metodologia para os cálculos dos custos operacionais regulatórios da ANEEL, que representam desafios para garantia do equilíbrio entre modicidade tarifária e sustentabilidade do setor de distribuição de energia elétrica, considerando-se aspectos qualitativos de satisfação de clientes e desempenho na continuidade de fornecimento de energia elétrica.

Palavras-Chave: Distribuição de Energia Elétrica no Brasil; ANEEL; Data Envelopment Analysis (DEA); Índice de Eficiência Técnica.

\begin{abstract}
This paper investigates the measurement process of technical efficiency indexes for the 30 largest power utilities in Brazil. Thus, it confronts the methodology of the ANEEL (regulatory agency) for the assessment of regulatory operational costs of the periodic tariff front review cycle with the proposed alternative methodology to observe the technical efficiency of performance of these companies combining aspects of quality of service to the society. Therefore, we used the Data Envelopment Analysis (with DEA models oriented input). Two scenarios were adopted: in $\mathrm{C} 1$, we observe the quantitative variables adopted by ANEEL, and in $\mathrm{C} 2$, we analyze service quality variables. Thus, based on performance results relative to the reporting period, technical efficiency measures are identified with positive development trend, for all of the 30 largest power utilities. Finally, it exposes some considerations about the need to improve some points in the methodology for the calculation of
\end{abstract}


regulatory operational costs by ANEEL, representing challenges to guarantee the balance between low rates and sustainability of the electricity distribution sector, considering aspects of quality through customer satisfaction and performance in the continuity of electricity supply.

Keywords: Electricity Distribution in Brazil; ANEEL; Data Envelopment Analysis (DEA); Technical Efficiency Index.

\section{INTRODUÇÃO}

Os deveres do Estado vêm se transformando ao longo dos anos, de modo que hoje, ele não se ocupa apenas com a provisão de equipamentos e serviços para a população, mas também, com a tarefa de propiciar a transparência e a participação da sociedade. A partir da criação da ANEEL (Agência Nacional de Energia Elétrica), no âmbito regulatório, procurou-se garantir a viabilidade econômica da atividade de distribuição de energia elétrica com o menor custo factível, dado determinado nível de qualidade na prestação do serviço, sem o repasse de encargos desnecessários ou excessivos aos consumidores finais. (PINTO JÚNIOR et al., 2007).

Assim, aspectos relacionados com a Teoria de Regulação Econômica ressurgem com força no cenário econômico brasileiro (destacando-se a sua grande aplicabilidade em diversos países do mundo), sendo desenhada para substituir o chamado ñmercadoò (regulação pelo retorno do investimento) e cabe a ela a fixação de incentivos e de restrições que permitam simular condições competitivas em busca da eficiência econômica, em função da característica de monopólio natural dessa atividade (ANEEL, 2006 e 2011). Em linha geral, o processo de reestruturação da indústria de energia elétrica brasileira visou à implantação de um sistema competitivo de mercado, onde: "a eficiência econômica das empresas como um todo representa a autossustentação da indústria de modo a garantir a expansão do sistema, a operação do sistema com elevado grau de confiabilidade e de qualidade e a prestação dos serviços de forma universal e não discriminatória." (SILVA, 2001, p. 18).

Todavia, este processo de reestruturação em si só não garantiu a extensão e a permanência dos benefícios da competição na indústria de energia elétrica, pois, como argumentou Gomes (1998), o desempenho de uma empresa "sofrerá a influência da estrutura do mercado, da própria conduta e a dos concorrentes ou entrantes potenciais e ainda da regulação de incentivo à eficiência econômica".

Os valores das tarifas de energia elétrica cobradas aos consumidores pelas empresas concessionárias de distribuição podem ser alterados pela ANEEL, durante o processo de revisão tarifária, para mais ou para menos. Isso dependerá das mudanças ocorridas nos custos e no mercado das empresas, da comparação dessas tarifas com as de outras empresas semelhantes, da eficiência da empresa. Contudo, é preciso permitir a manutenção do equilíbrio econômico-financeiro das concessionárias. Desta forma, tanto no $1^{\circ}$ Ciclo de Revisão Tarifária Periódica (1CRTP) como no $2^{\circ}$ (2CRTP), observou-se que a ANEEL adotou como metodologia básica para determinação dos custos operacionais eficientes a Empresa de Referência que, de forma simplificada, pode ser entendida como a representação matemática da atividade de distribuição de energia elétrica, definindo cada ação e cada processo adotado pelas distribuidoras, bem como seus custos médios parametrizados (ANEEL, 2006).

Essa metodologia da Empresa de Referência foi totalmente reformulada no 2CRTP após ampla discussão na Audiência Pública (AP 052/2007). A grande inovação deu-se com a introdução da análise de consistência global, que trouxe uma segunda dimensão na definição dos custos operacionais. Com esta nova condição regulatória do setor elétrico brasileiro estimula-se a competição entre os agentes setoriais, exigindo eficiência na gestão dos custos operacionais, otimização do planejamento e execução orçamentária e, principalmente, uma engenharia financeira bem articulada 
com as oportunidades do mercado (distribuição e comercialização). Estes últimos aspectos passaram a ser determinantes, em muitos casos, na competitividade dos investidores.

Ademais, com a implementação dos Procedimentos de Regulação Tarifária (PRORET), que estabelecem as metodologias aplicáveis ao $3^{\circ}$ Ciclo de Revisão Tarifária Periódica (3CRTP) e ao $4^{\circ}$ Ciclo de Revisão Tarifária Periódica (4CRTP), buscou-se preservar os princípios e fundamentos que balizaram a definição dos custos operacionais nos ciclos anteriores, introduzindo aperfeiçoamentos significativos na metodologia anteriormente utilizada, podendo se destacar a simplificação do modelo, o foco nos custos eficientes em análise a nível global, e não mais pormenorizada.

Com isso, e para atingir os objetivos estabelecidos pela ANEEL, confirmou-se a introdução de novas ferramentas, como a aplicação de uma metodologia de benchmarking, intitulada Data Envelopment Analysis ï DEA. Esta tem finalidade similar ao modelo de Empresa de Referência, contudo é menos intensiva em dados e informações. Até então esta metodologia não era utilizada na definição dos custos operacionais das concessionárias de energia elétrica no Brasil, mas conforme Pessanha et al. (2010), a utilização desta para avaliação dos indicadores de eficiência já está bem disseminada entre os agentes reguladores do setor elétrico mundial. Além do mais, a metodologia DEA representa o referencial teórico ideal para a implementação prática de estratégias de regulação por comparação, visto que se avaliam os índices de eficiência de cada concessionária e identifica o melhor padrão de desempenho, que deverá ser seguido pelas demais, fornecendo ao processo regulatório uma maior transparência. (BOGETOFT e NIELSEN, 2003).

Assim, a temática desta pesquisa vem contribuir neste processo na medida em que visa realizar uma investigação sobre a mensuração dos escores de eficiência de empresas distribuidoras de energia elétrica no Brasil, dado as informações disponibilizadas pela ANEEL. E confronta-se a metodologia da Agência Nacional de Energia Elétrica (ANEEL) para a avaliação dos custos operacionais regulatórios do ciclo de revisão tarifária periódica frente à metodologia alternativa proposta para observar o desempenho de eficiência técnica destas empresas associando aspectos de qualidade dos serviços prestados à sociedade. Ademais, nesta comparação, utilizam-se os modelos DEA orientados para insumo: o CRS (Constant Returns to Scale), o VRS (Variable Returns to Scale) e o NDRS (Non-Decreasing Returns to Scale), que presumem tecnologias com os seguintes retornos à escala de produção: constantes, variáveis e não decrescentes, respectivamente.

\section{REFERENCIAL TEÓRICO}

\subsection{Regulação Econômica}

Muitos acreditam que as soluções dos problemas econômicos estejam ligadas à competição, e que o monopólio seja o causador das imperfeições diante da busca do bem-estar social. Assim, tem-se que:

Os mercados competitivos têm se mostrado desejáveis, porque eles se apresentam economicamente eficientes, desde que não haja externalidades20 e nada impeça o funcionamento do mercado, a soma total de excedente do consumidor e do produtor será a maior possível. (PYNDICK e RUBINFELD, 1994, p.556).

O monopólio exerce um forte custo social e a regulação é um instrumento que busca evitar que determinadas empresas acumulem excessivamente o poder de monopólio. Em geral, destacam Pinto Júnior e Fiani, (2013), a regulação ocorre através de leis antitrustes ou pela regulamentação de preços, um recurso que pode eliminar a perda bruta, resultante deste poder de mercado. Nos setores onde 
predominam o monopólio natural, como as concessões de redes de distribuição de energia elétrica, a regulação de preços é mais frequente.

A legislação antitruste, por sua vez, procura limitar o poder de mercado, seja dos vendedores ou, seja dos compradores, onde suas ações, se livres, resultariam em uma perda bruta. O excessivo poder de mercado também ocasiona problemas de falta de equidade e imparcialidade: se uma empresa possui um significativo poder de monopólio, ela estará lucrando à custa dos consumidores. (PINTO JÚNIOR e FIANI, 2013).

O objetivo central da regulação econômica não é buscar a competição como um fim em si mesmo, mas utilizar da concorrência para alcançar eficiência econômica nos mercados. E conforme Possas:

A regulação das atividades da indústria de energia elétrica promove, tanto quanto possível, um ambiente competitivo, favorável à prática de preços não monopolistas e à qualidade dos serviços prestados, bem como à incorporação e difusão de novas tecnologias e serviços mais modernos, tendo em vista atingir a eficiência econômica e o bem-estar social. (POSSAS, 1997, p. 87)

Também para Possas et al. (1997), a eficiência técnica consiste na utilização, com máximo rendimento e mínimo custo, da estrutura produtiva instalada e sua respectiva tecnologia. Enquanto que a eficiência alocativa tornou-se (dado a sua aplicação nas áreas de microeconomia e economia industrial), praticamente, sinônimo de eficiência econômica, tendo sua origem no ótimo de Pareto. Assim, considera-se que o máximo de transações é alcançado neste ponto, onde maior renda é gerada e que os agentes estão num grau ótimo de satisfação, pois não podem melhorar sua situação sem prejudicar a de outro.

$\mathrm{Na}$ indústria de energia elétrica do Brasil, tradicionalmente, verifica-se dois mecanismos de regulação econômica de custos para empresas monopolistas (ver Quadro 1), ou seja, a tarifação pela taxa interna de retorno (também chamada de tarifação pelo custo do serviço), não mais utilizada, e a tarifação price cap (preço teto), utilizada atualmente.

Quadro 1 - Características dos Principais Mecanismos de Regulação Econômica Usados na Indústria de Energia Elétrica no Brasil

\begin{tabular}{|c|c|c|}
\hline $\begin{array}{c}\text { Tipo de } \\
\text { Mecanismo }\end{array}$ & $\begin{array}{c}\text { Taxa Interna de Retorno } \\
\text { (Regulação pelo Retorno do } \\
\text { Investimento) }\end{array}$ & $\begin{array}{c}\text { Price Cap } \\
\text { (Regulação por Incentivos) }\end{array}$ \\
\hline $\begin{array}{c}\text { Objetivos / } \\
\text { Características }\end{array}$ & $\begin{array}{l}\text { - Garantir o reajuste de preços que permita } \\
\text { o reembolso integral dos custos }\end{array}$ & $\begin{array}{l}\text { - Garantir um preço teto, menos um } \\
\text { índice negociável X, fixado ex ante }\end{array}$ \\
\hline $\begin{array}{l}\text { Pontos Fortes / } \\
\text { Vantagens }\end{array}$ & $\begin{array}{l}\text { - Assegurar a viabilidade econômica da } \\
\text { empresa } \\
\text { - Estimular o investimento, aspecto } \\
\text { importante em fase de forte expansão }\end{array}$ & $\begin{array}{l}\text { - Proteção dos consumidores } \\
\text { - Estimular a redução de custos }\end{array}$ \\
\hline $\begin{array}{l}\text { Pontos Fracos } \\
\text { /Desvantagens }\end{array}$ & $\begin{array}{l}\text { - Tendência à má alocação de recursos } \\
\text { - Multiplicação de reajustes } \\
\text { - Nenhum estímulo à redução de custos }\end{array}$ & $\begin{array}{l}\text { - Necessidade de definição de um padrão } \\
\text { mínimo de qualidade } \\
\text { - Critério para revisão do parâmetro X } \\
\text { (assimetria de informação) } \\
\text { - Se o ambiente econômico é incerto: o } \\
\text { cap é alto, ou o prazo para a revisão de } \\
\text { X é longo }\end{array}$ \\
\hline $\begin{array}{l}\text { Incentivo à } \\
\text { Eficiência } \\
\text { Econômica }\end{array}$ & $\begin{array}{l}\text { - Tarifação focada mais na eficiência } \\
\text { alocativa, porém não são eficazes para } \\
\text { incentivar a redução de custos }\end{array}$ & $\begin{array}{l}\text { - Tarifação orientada para a busca da } \\
\text { eficiência técnica, mas são } \\
\text { insatisfatórios no tocante à eficiência } \\
\text { alocativa }\end{array}$ \\
\hline
\end{tabular}

Fonte: Compilação Própria com base em PINTO JÚNIOR, (2007) e PINTO JÚNIOR, e FIANI (2013).

RE\&D Econ. e Desenv., Santa Maria, vol. 28, n.1, p. 326 - 344, jan. ï jun. 2016 
E como se verifica no Quadro 1, ambos os mecanismos possuem pontos fortes e fracos, e em todas as formas há limitações no sentido da necessidade de muitas informações, tornando-se difícil julgar qual deles pode ser considerado o melhor.

\subsection{Regulação Econômica e Eficiência Técnica}

Considerando-se a ótica do produtor, a tarifação pela taxa interna de retorno é vantajosa, pois este tem assegurada a remuneração de seu investimento. No entanto, existem limites para a remuneração dos investimentos, cabendo ao regulador suprimir da base de cálculo aqueles para os quais não haja justificativa econômica. Todavia, este tipo de aparato regulatório contém algumas limitações. A primeira delas é a dificuldade de determinação do valor-base, isto é, o investimento sobre o qual se aplica a taxa de retorno. Ainda, a avaliação do custo de capital a ser utilizado como balizador da taxa de remuneração também é um processo complexo, pois cada empresa possui uma estrutura de capital diferente e nem todas as empresas possuem ações cotadas em bolsas. E as assimetrias de informação entre o regulador e a empresa podem levar à manipulação de dados por parte desta última, com o objetivo de apropriação de lucros extraordinários.

Assim, destaca-se que, na hipótese de a taxa de retorno estar acima do custo de capital, este critério dará origem ao efeito Averch-Johnson, ou seja, as empresas são estimuladas a um sobreinvestimento, pois a sobreutilização do capital proporciona uma remuneração da taxa de desconto superior à depreciação deste capital, gerando um uso subótimo da instalação. Entretanto, em períodos de elevação da taxa de juros e de incerteza macroeconômica, a tendência é inversa. (PIRES, 2000).

Já a tarifação price cap estabelece um preço-teto para os produtos e serviços oferecidos por uma empresa e propõe uma solução de incentivo à eficiência técnica, pois com os preços limitados, o produtor seria estimulado a reduzir custos para auferir lucros maiores. Todavia, também apresenta algumas dificuldades, diferente da tarifação pela taxa interna de retorno, pois ela não se preocupa com custos históricos, e possui uma tendência prospectiva. Ao fixarem-se os preços, as empresas se comportam estrategicamente tendo em vista as futuras revisões. Dessa forma, quando a revisão de preços se aproxima, as empresas têm pouco estímulo para conter seus custos, para que o órgão regulador fixe um menor fator $\mathrm{X}$ para o novo preço. Além disso, o órgão regulador deve ficar atento para os padrões de qualidade dos serviços prestados, pois as empresas podem sacrificá-los de forma a abaixar custos.

Outra questão, como constatada em Santana e Gomes (1999), se refere à vulnerabilidade do price cap quanto à variação de custos exógenos, que não são controláveis pela empresa, como por exemplo, uma brusca variação na demanda. Assim, as empresas com elevados custos fixos, submetem-se ao risco de uma queda brusca na demanda, sem que seus custos possam ser reduzidos de forma significativa.

Por outro lado, as empresas de elevados custos variáveis ficam fragilizadas com o risco da elevação brusca na demanda, visto que os custos serão repassados ao consumidor somente no próximo período de revisão tarifária.

\subsection{Data Envelopment Analysis (DEA)}

Data Envelopment Analysis (DEA) é uma técnica baseada em programação linear, com o objetivo de medir o desempenho de unidades operacionais ou tomadoras decisão, as chamadas Decision Marking Units (DMUs), quando a presença de múltiplas entradas e múltiplas saídas torna difícil a realização de uma comparação entre elas.

Essa técnica foi desenvolvida por Charnes, Cooper e Rhodes, em 1978, com base nos conceitos de Eficiência Pareto-Koopmans, desenvolvido em 1951, por Koopmans, e de Eficiência de 
Farell, desenvolvidos em 1957, afirma que uma organização é completamente eficiente se, e somente se, não é possível aumentar nenhum insumo ou produto sem diminuir algum outro insumo ou produto (pressupondo que a tecnologia da fronteira de eficiência exibe retornos de escala constantes). Ainda, a metodologia recebeu contribuições de Banker, Charnes e Cooper, em 1984, que propuseram análise sobre a tecnologia da fronteira de eficiência a partir de retornos de escala variáveis. Assim, o termo DEA passou a ser utilizado para descrever o método de análise de eficiência, baseado na programação matemática, conhecido também como método não paramétrico. (NORMAN e STOCKER, 1991).

A metodologia DEA permite comparar as eficiências relativas entre organizações homogêneas (DMUs), que possuem um mesmo conjunto de insumos para produzir um mesmo conjunto de produtos, através de processos tecnológicos similares para determinar a sua eficiência técnica.

Neste trabalho, a DMU será uma Empresa Distribuidora de Energia Elétrica (EDEE). O objetivo da metodologia é construir um conjunto de referência convexo de forma que as EDEEs podem ser classificadas em unidades eficientes e ineficientes, tendo como referencial essa superfície formada. E os índices obtidos através da especificação na modelagem, via programa computacional livre EMS(Efficiency Measurement System), representam as medidas de eficiência técnica para as respectivas DMUâs.

Assim, graficamente, seja a isoquanta eficiente apresentada na Figura 1, formada pelas EDEEs $\mathrm{A}, \mathrm{B}$ e $\mathrm{C}$ e os segmentos (vertical e horizontal) paralelos aos eixos das quantidades dos insumos $\mathrm{x} 1 \mathrm{e}$ x2, cuja linha PPòrepresenta a razão entre seus preços.

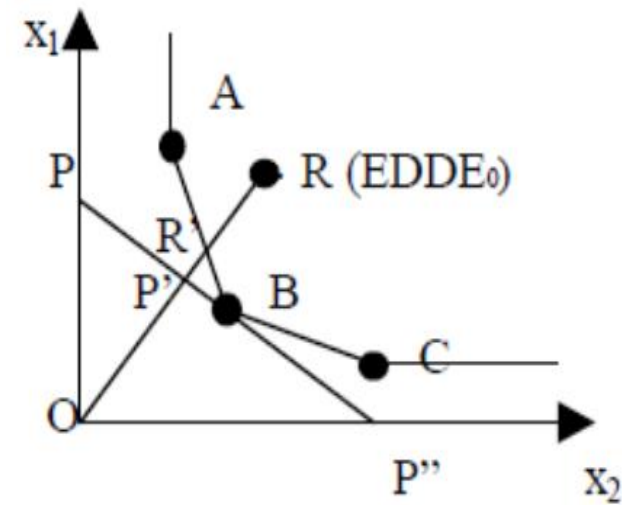

FIGURA 1 - Isoquanta eficiente formada pelas EDEEs A, B e C, e R sendo ineficiente.

Pode-se observar na Figura 1 que a EDEE que corresponde ao ponto $\mathrm{R}$ não está sobre a referida fronteira eficiente e, portanto, é uma EDEE ineficiente. A distância OR/ORôé a medida de sua eficiência técnica (IET) e (1-OR/ORô mede a redução equiproporcional, nas quantidades dos insumos x1 e x2 necessária para que a mesma EDEE se torne eficiente.

Já a distância radial ORốOPômede a eficiência alocativa (IEA) da EDEE, e sua eficiência econômica (IEE) será dada pelo produto entre as medidas de eficiência técnica (IET) e de eficiência alocativa (IEA), isto é: IEE = IET x IEA. Desta forma, para Possas et al. (1997), a eficiência técnica consiste na utilização, com máximo rendimento e mínimo custo, da estrutura produtiva instalada e sua respectiva tecnologia. Enquanto que a eficiência alocativa tornou-se (dado a sua aplicação nas áreas de microeconomia e economia industrial), praticamente, sinônimo de eficiência econômica, tendo sua origem no ótimo de Pareto.

De acordo com Thanassoulis (2001), na aplicação do DEA devem constar alguns procedimentos básicos: (a) as organizações devem ser homogêneas, sendo necessário analisar um conjunto que realiza as mesmas tarefas e possuem objetivos semelhantes; (b) as organizações devem atuar sob as mesmas condições de mercado; e (c) as variáveis (insumos e produtos) devem ser as 
mesmas para cada conjunto analisado, apresentando variações apenas quanto à intensidade ou magnitude.

Os modelos DEA apresentam uma sequência de etapas que podem ser compreendidas nas fases: (a) seleção das EDEEs a entrarem na análise; (b) seleção das variáveis (insumos e produtos) que são relevantes e apropriadas para estabelecer a eficiência relativa das EDEEs selecionadas; e (c) identificação e aplicação dos modelos. Além disso, deve evitar-se o uso de um modelo com grande número de variáveis e sem relação de causalidade.

\subsubsection{Modelo CCR (DEA CRS)}

As formulações básicas da metodologia DEA, desenvolvidas por Charnes, Cooper e Rhodes (com o modelo DEA CCR, em homenagem aos pioneiros autores), são caracterizadas por tecnologias com retornos constantes à escala de produção, chamado também de modelo DEA CRS (Constant Returns to Scale), utilizando múltiplos inputs e outputs, por meio de técnicas não paramétricas. Esse modelo permite uma avaliação objetiva da eficiência global e identifica as fontes e estimativas de montantes das ineficiências. No modelo DEA CCR, quando uma EDEE é eficiente, nenhuma outra EDEE com seu mesmo tamanho apresenta maior eficiência do que ela. E quando uma EDEE é ineficiente, essa ineficiência pode ser decomposta em ineficiência de escala e em ineficiência técnica. (SEIFORD E ZHU, 1999).

\subsubsection{Modelo BCC (DEA VRS)}

Já Banker, Charnes e Cooper (com o modelo o DEA BCC, em homenagem aos autores), elaboraram o modelo também chamado DEA VRS (Variable Returns to Scale) com retorno variável de escala, permitindo, também, que empresas que atuam sob retornos crescentes e decrescentes fossem avaliadas. Esse modelo estabelece distinção entre ineficiências técnicas e de escala, estimando a eficiência técnica pura, a uma dada escala de operações, e identificando se estão presentes ganhos de escala crescente, decrescente ou constante, para futura exploração. (SEIFORD e ZHU, 1999).

Complementarmente, na Figura 2, estão representadas as seguintes fronteiras de produção no espaço insumo x produto: o raio $\mathrm{OBC}$ define a fronteira de produção que exibe retornos constantes à escala (CRS); a fronteira de produção definida pelos segmentos $\mathrm{AB}, \mathrm{BC}$ e $\mathrm{CD}$ definem a fronteira de produção que exibe retornos variáveis à escala (VRS), isto é, retornos crescentes à escala de produção (IRS), retornos constantes à escala de produção (CRS) e retornos decrescentes à escala (DRS); os segmentos $\mathrm{OBC}$ ou $\mathrm{ABC}$ definem a fronteira que exibe retornos não decrescentes à escala (NDRS). $\mathrm{E}$ os segmentos $\mathrm{OBCD}$ definem a fronteira que exibe retornos não crescentes à escala (NIRS).

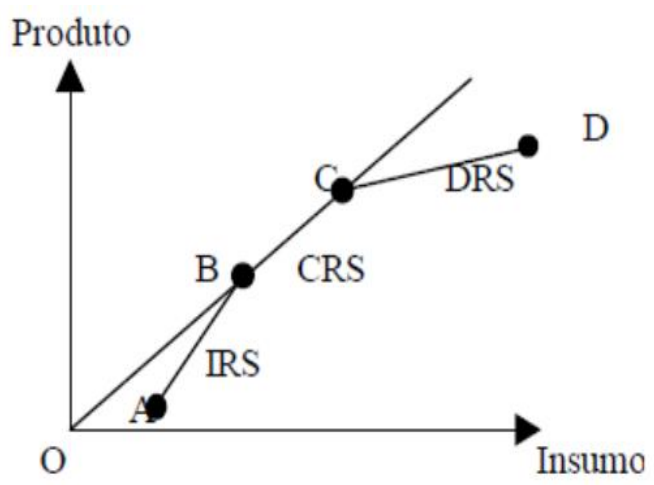

FIGURA 2 - Fronteira de produção.

No segmento $\mathrm{AB}$ prevalecem os retornos crescentes à esquerda de $\mathrm{B}$ e, no segmento $\mathrm{CD}$, os retornos decrescentes prevalecem à direita de C. Nos pontos situados na interseção de segmentos com diferentes retornos à escala de produção prevalecem os retornos constantes. 


\section{ANÁLISE DE DADOS SOBRE AS DISTRIBUIDORAS DE ENERGIA ELÉTRICA DO BRASIL}

Esta pesquisa analisou as 30 maiores empresas distribuidoras de energia elétrica do Brasil, classificadas pela ANEEL como pertencentes ao chamado Grupo A (com mercado maior que $1 \mathrm{TWh}$ ), considerando-se o universo de 64 concessionárias existentes no país distribuídas no Grupo A (com 33 empresas) e no Grupo B (com 31 empresas e com mercado menor que 1 TWh). Estas 30 concessionárias são responsáveis pela disponibilização ao consumo de 389,69 TWh, representando 94,95\% da energia elétrica distribuída e faturada no Brasil em 2012 (que totaliza um valor na ordem de 410,42 TWh).

Com relação ao tipo de gestão empresarial do conjunto de empresas distribuidoras de energia elétrica analisadas neste trabalho, constata-se que 8 empresas da amostra são empresas públicas (27\%), enquanto que 22 empresas da amostra são de gerenciamento privado (73\%). O universo da pesquisa contempla empresas distribuidoras de energia elétrica de todas as regiões geográficas do país.

\subsection{As Variáveis da Pesquisa}

As informações técnicas referentes aos indicadores foram coletados junto à ANEEL (ver APÊNDICE A), e elaborou-se um banco de dados para realização dos estudos referentes ao $3^{\circ}$ Ciclo de Revisão Tarifária Periódica (3CRTP).

As variáveis aplicadas na metodologia DEA para determinação dos custos operacionais regulatórios de modo a mensurar-se a eficiência técnica das empresas distribuidoras de energia elétrica do Brasil, caracterizadas como insumo e produto, são:

- Custo Operacional - OPEX (R\$), como insumo;

- Extensão de Redes de Distribuição de Energia Elétrica - Rede (km), como produto;

- Consumo de Energia Elétrica - Mercado (TWh), como produto;

- Número de Unidades Consumidoras de Energia Elétrica Ï UC ( ${ }^{\circ}$ de Clientes), como produto;

- Inverso do Indicador de Desempenho Global de Continuidade - InvDGC (indicador), como produto;

- Indicador ANEEL de Satisfação do Cliente Ï IASC (indicador), como produto.

\subsection{Resultados}

A seguir, são apresentados os resultados referentes às medidas de eficiência técnica (avaliando-se o conjunto quanto ao retorno à escala de produção), obtidos através modelagem DEA (rodando-se os modelos DEA CRS, DEA VRS e DEA NDRS para cada ano, separadamente) no conjunto de variáveis (insumos e produtos), para as 30 maiores distribuidoras de energia elétrica brasileiras, considerando-se os dois cenários apresentados a seguir (ver Figura 3): 


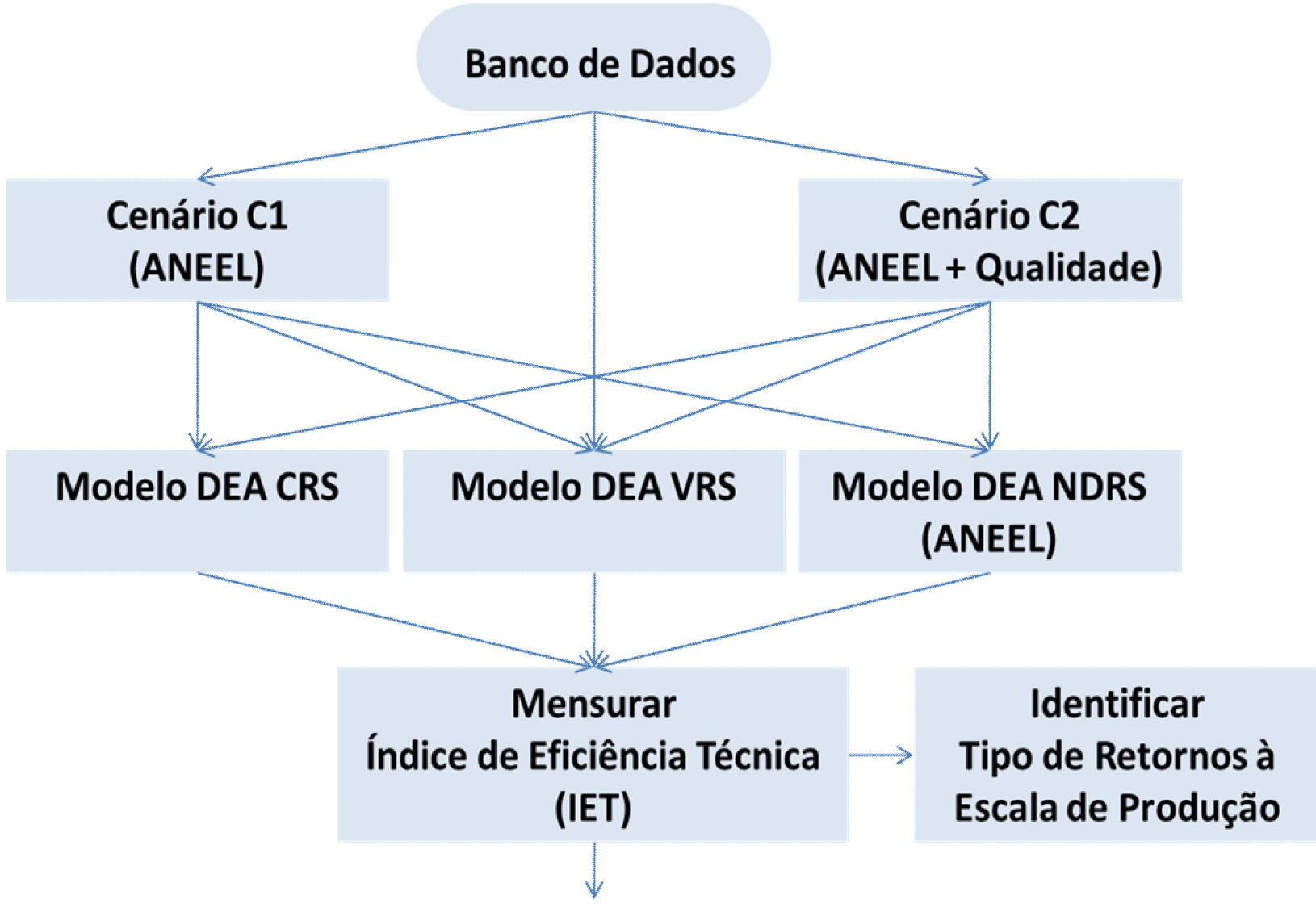

\section{Classificar as Empresas}

FIGURA 3 ï Fluxograma de aplicação da metodologia proposta para mensuração de eficiência.

Notas: a) Cenário C1, contempla as variáveis usadas pela ANEEL (OPEX, Rede, Mercado e UC);

b) Cenário C2, aborda as variáveis ANEEL (C1) e as variáveis de qualidade reguladas (InvDGC + IASC).

Os resultados obtidos quanto à eficiência técnica, considerando o cenário $\mathrm{C} 1$, observa-se para o modelo DEA CRS um valor mediano igual a $64,19 \%(0,6419)$ de eficiência técnica. Já no modelo DEA VRS o valor mediano é igual a 75,04\% $(0,7504)$ de eficiência técnica. E para o modelo DEA NDRS o valor mediano é igual a $68,31 \%(0,6831)$ de eficiência técnica.

E considerando o cenário C2, observa-se para o modelo DEA CRS o valor mediano igual a $68,18 \%(0,6818)$ de eficiência técnica. Para o modelo DEA VRS o valor mediano é igual a 80,28\% $(0,8028)$ de eficiência técnica. E para o modelo DEA NDRS verifica-se um valor mediano igual a $69,81 \%(0,6981)$ de eficiência técnica.

Assim, percebe-se que os resultados do cenário C1 (com apenas variáveis ANEEL) dos scores medianos de eficiência técnica, para os 3 modelos DEA utilizados, são menores que os resultados obtidos para o cenário $\mathrm{C} 2$, que além das variáveis ANEEL apresenta variáveis de qualidade reguladas. $\mathrm{O}$ cenário $\mathrm{C} 2$ apresenta-se sempre com valores percentuais maiores, onde estas diferenças à maior são na ordem de: 4,20\% no modelo DEA C2-CRS, de 1,42\% no modelo DEA C2-NDRS e de 4,44\% no modelo DEA C2-VRS.

Sob o ponto de vista de evolução dos índices de eficiência técnica das 30 maiores distribuidoras de energia elétrica no Brasil (2003-2009), pode-se observar na Figura 4 que para o cenário $\mathrm{C} 1$ todas as modelagens DEA (CRS, VRS e NDRS) utilizadas na análise apresentaram uma evolução positiva (na mediana) de 2003 para 2009, embora se tenha oscilações (positivas e negativas) 
neste intervalo de tempo. No cenário $\mathrm{C} 2$ também se percebe situação semelhante para todas as modelagens DEA (CRS, VRS e NDRS) que apresentaram uma evolução positiva (na mediana) no período, no entanto a mediana dos índices de eficiência de todos os modelos para esse cenário foi sempre maior ou igual às do cenário $\mathrm{C} 1$.

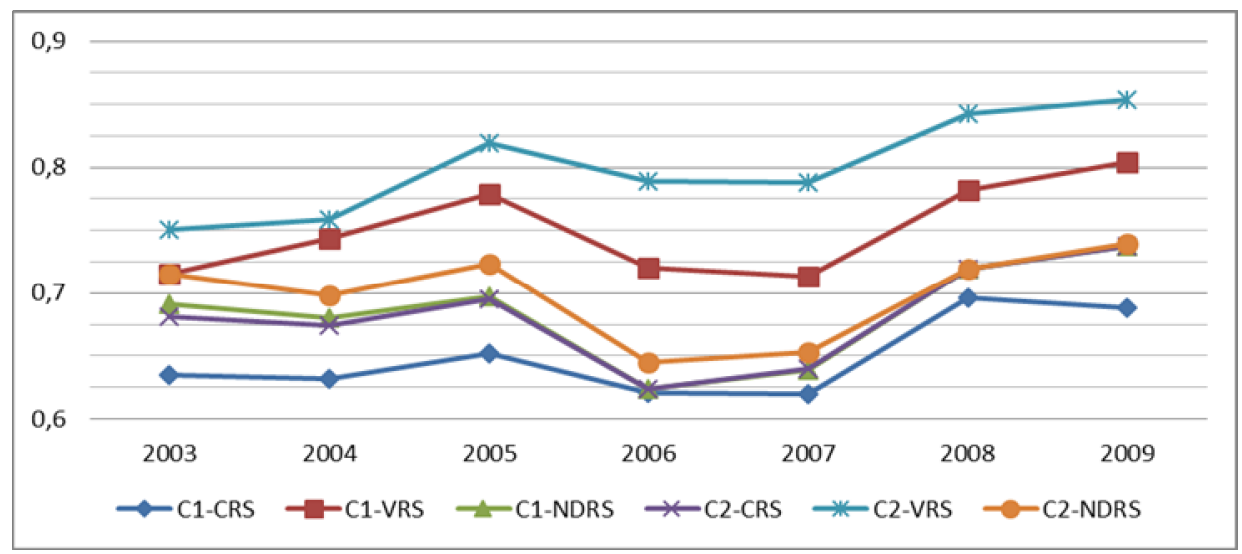

FIGURA 4 - Mediana da Evolução dos Índices de Eficiência Técnica (Cenários C1 e C2) das 30 Maiores Distribuidoras de Energia Elétrica no Brasil.

Na sequência, tem-se na Figura 5 um ranking das distribuidoras de energia elétrica no Brasil, considerando-se os dois cenários analisados frente às modelagens DEA CRS, VRS e NDRS a partir dos valores medianos dos índices de eficiência técnica, para os anos compreendidos entre 2003 e 2009.

Com os resultados obtidos nas modelagens DEA comparativas entre os cenários analisados com base na Figura 5 (a), (b) e (c) (C1-CRS, C2-CRS; C1-VRS, C2-VRS; C1-NDRS e C2-NDRS) percebe-se que existem divergências nas listagens classificatórias de eficiência técnica (benchmarking) dessas empresas entre os diferentes cenários e modelagens DEA testados. Destaca-se a evidente inversão nas listagens classificatórias no caso específico da CEMIG (grande porte empresarial), que apresentou medidas medianas de forte ineficiência técnica na modelagem DEA CRS (C1 igual a $0,5598$ e C2 igual a 0,5598) e na modelagem DEA NDRS (C1 igual a 0,5598 e $\mathrm{C} 2$ igual a $0,55,98)$ e apresentou medidas medianas de máxima eficiência na modelagem DEA VRS (C1 igual a 1,0000 e C2 igual a 1,0000$)$.

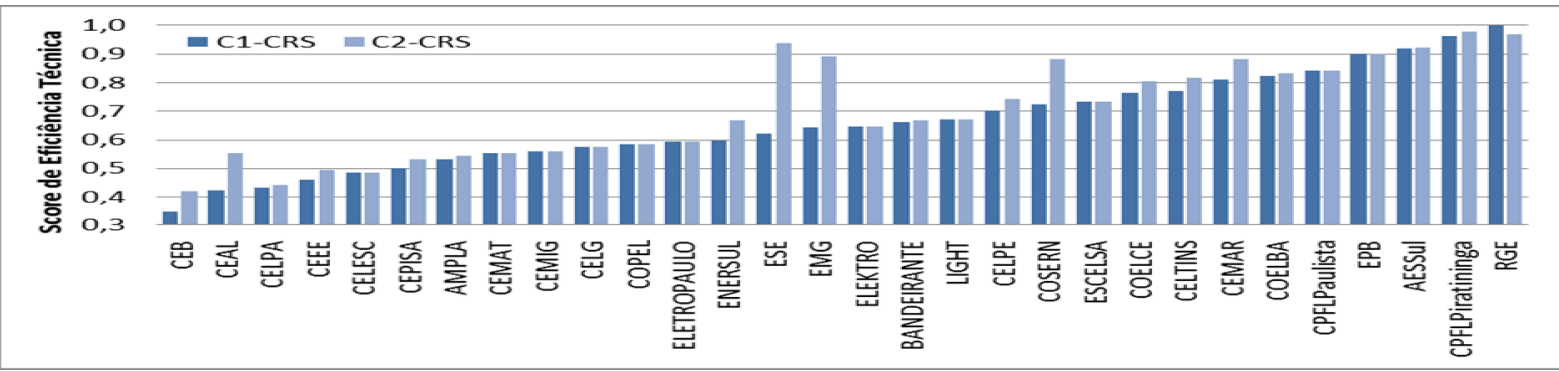

(a)

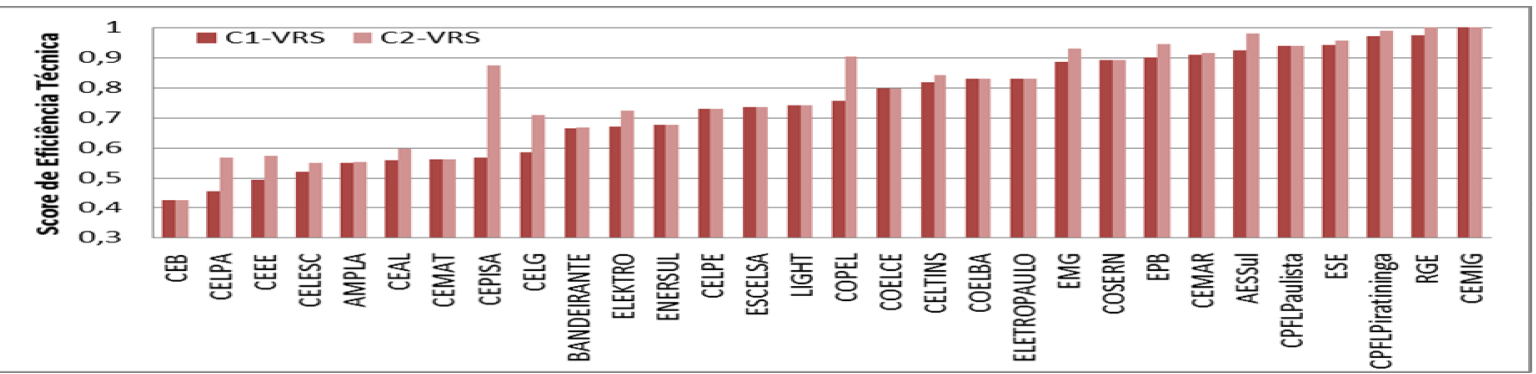

(b)

RE\&D Econ. e Desenv., Santa Maria, vol. 28, n.1, p. 326 - 344, jan. ï jun. 2016 


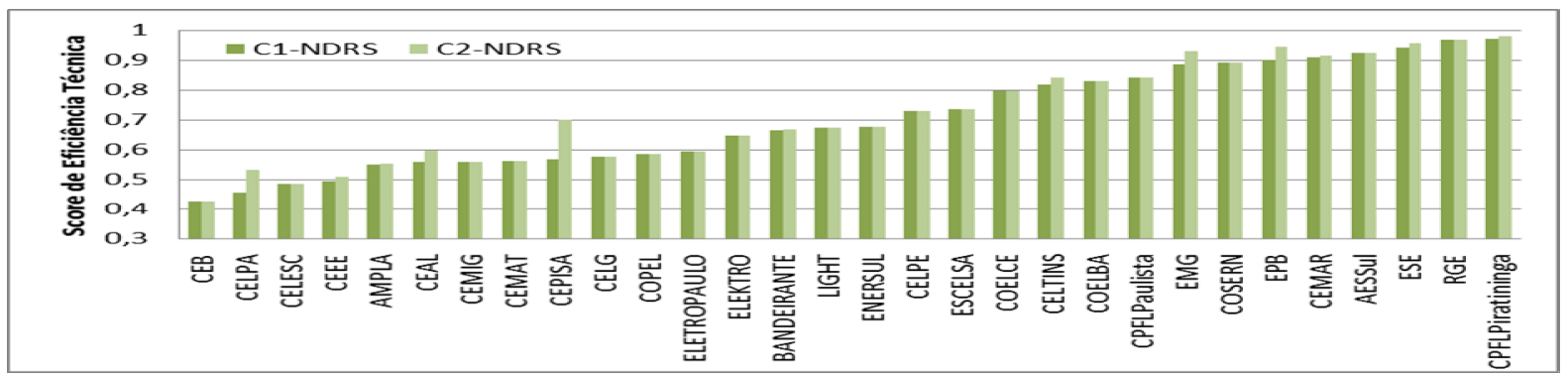

(c)

FIGURA 5 - Ranking das Distribuidoras de Energia Elétrica pelo Índice de Eficiência Técnica para as modelagens DEA CRS (a), DEA VRS (b) e DEA NDRS (c), nos cenários C1 e C2.

Fazendo uma análise agrupada para os 210 resultados obtidos a partir das especificações para as modelagens DEA, quanto ao retorno de escala de produção, no software EMS, referentes as 30 empresas distribuidoras de energia elétrica, observa-se no cenário C2 que 95 EDEEs (45\%) exibiram retornos de escala crescentes (IRS) e apresentam um tamanho inferior ao tamanho mais produtivo. Já 105 EDEEs (50\%) exibiram retornos de escala decrescentes (DRS) e apresentam um tamanho superior ao tamanho mais produtivo.

De todo modo, testes estatísticos realizados em estudos críticos baseados na aplicação da metodologia DEA, referentes aos retornos de escala de produção para as concessionárias de distribuição de energia elétrica brasileiras, defendem a aplicação do modelo DEA VRS, uma vez que observaram uma maior sensibilidade à retirada das maiores empresas da amostra. (BANKER, 2011; MATOS, LOPES, E COSTA, 2012).

\section{CONSIDERAÇÕES FINAIS}

Os resultados obtidos demonstram que apesar da metodologia DEA demandar menos informações e ser mais robusta quanto a críticas de modelagem em relação à empresa de referência, tem-se que a escolha do modelo pode afetar drasticamente a classificação da eficiência técnica de uma empresa de distribuição de energia elétrica. Especialmente no caso do modelo DEA CRS, que penaliza severamente empresas que trabalhem com retornos de escala decrescentes em algum momento, apesar de serem eficientes do ponto de vista do modelo DEA VRS, nem valoriza os ganhos de escala crescentes, como faz o modelo DEA NDRS. Portanto, a adoção de um modelo DEA VRS buscará contemplar e captar as condições reais observadas, em termos de desempenho (eficiência técnica), no ambiente de gestão das distribuidoras de energia elétrica no Brasil.

Desta forma, este trabalho pode servir de um ponto de partida para futuras investigações, mais detalhadas para determinar possíveis fontes de ineficiência, ou até mesmo para pesquisar sobre as diferenças de desempenho entre as EDEEs avaliadas, servindo como informação adicional para a tríade envolvida neste processo (ANEEL, Concessionárias e Clientes), visto que são apresentados resultados de avaliação relativa sobre o desempenho destas distribuidoras de energia elétrica.

E conectando-se os aspectos de evolução dos índices de eficiência técnica para as 30 maiores distribuidoras de energia elétrica no Brasil com a temática de regulação econômica vivenciada no país, verificou-se que este conjunto de empresas, na mediana, operou com crescimento da medida de eficiência técnica (com pequenas oscilações verificadas no intermédio do período) considerando-se o início do período em 2003 e o fim do período em 2009, foram decorrentes de mudanças importantes no segmento de distribuição de energia elétrica, ocorridas entre outros fatores através da implantação de inovações tecnológicas associadas às inovações na gestão empresarial (paradigma público x

Econ. e Desenv., Santa Maria, vol. 28, n.1, p. 326 - 344, jan. ï jun. 2016 RE\&D 
privado), buscando-se as melhores estratégias para que sejam obtidas as maiores vantagens competitivas para as empresas enfrentarem as constantes mudanças regulatórias no setor elétrico brasileiro.

Em termos de qualidade dos serviços prestados, além dos indicadores regulados referentes ao nível de continuidade do fornecimento de energia elétrica (DGC, DEC, FEC, entre outros) e ao nível de satisfação do consumidor residencial (IASC), tem-se o processo de implantação da regulamentação através de indicadores do nível de qualidade do atendimento (tratamento das reclamações) previstas na Resolução Normativa ANEEL 414/2010, ou seja, o DER (Duração Equivalente de Atendimento à Reclamação, que se refere ao tempo médio para solução das reclamações procedentes) e o FER (Frequência Equivalente de Atendimento à Reclamação, que se refere à frequência de ocorrência de uma reclamação procedente a cada mil unidades consumidora). Como as concessionárias devem apurar os indicadores DER e o FER, através de um processo certificado, a ANEEL poderá até mesmo utilizar estes novos indicadores de modo a compor uma possível nova modelagem de determinação dos índices de eficiência técnica das concessionárias de energia elétrica.

Finalizando, verificou-se que avanços significativos foram alcançados no decorrer do período, destacando-se o aperfeiçoamento do modelo do setor elétrico brasileiro, através da garantia de segurança para novos investimentos (leilões com setor contratos de longo prazo), com o monitoramento e planejamento investimento das concessionárias para maior segurança do suprimento, com o incentivo às novas fontes de geração e com os programas de financiamento. Mas é necessário aprimorar alguns pontos, que representam desafios para garantia do equilíbrio entre modicidade tarifária e sustentabilidade do setor elétrico, considerando-se aspectos qualitativos voltados à satisfação de clientes e ao desempenho na continuidade de fornecimento de energia elétrica.

RE\&D Econ. e Desenv., Santa Maria, vol. 28, n.1, p. 326 - 344, jan. ï jun. 2016 


\section{REFERÊNCIAS BIBLIOGRÁFICAS}

ANEEL - Agência Nacional de Energia Elétrica (2006). Nota Técnica N 166/2006 ï SRE/ANEEL, Brasília, DF. [Online]. Disponível em: http://www.aneel.gov.br.

ANEEL - Agência Nacional de Energia Elétrica (2011). Nota Técnica No 293/2011 ï SRE/ANEEL, Brasília, DF. [Online]. Disponível em: http://www.aneel.gov.br.

BANKER, R. Report on ANEELô Proposal for Electricity Distribution Tariff Regulation Technical. Relatório Técnico. n. 101, Agência Nacional de Energia Elétrica (ANEEL), Brasília. DF, jun. 2011.

BAUMOL, W.J. Contestable Markets and the Theory of Industrial Structures. American Economic Review, n. 73 (3), p. 491-496, jun. 1983.

BOGETOFT, P.; NIELSEN, K. DEA Based Yardstick Competition in Natural Resource Management. In: Recent Accomplishments in Applied Forest Economics Research, F. Helle, N. Strange e L.Wichmann, Ed. Kluwer Academic Publisher. 2003. pp. 103-126.

GOMES, A. A. C. A Reestruturação das Indústrias de Rede: uma avaliação do setor elétrico brasileiro. Dissertação de Mestrado, Engenharia de Produção, Universidade Federal de Santa Catarina ï UFSC, Florianópolis ï SC, 1998.

MARINHO, E. L. L.; ATALIBA, F.; LIMA, F. Produtividade, variação tecnológica e variação de eficiência técnica das regiões e estados brasileiros. Estudos Econômicos. Instituto de Pesquisas Econômicas, São Paulo, v. 32, p. 367-407, 2002.

MATOS, G. B. B. P. LOPES, A. L. M.; COSTA, M. A. C. Avaliação do Modelo de Benchmarking Proposto pela Agência Nacional de Energia Elétrica para o Terceiro Ciclo de Revisões Tarifárias das Distribuidoras no Brasil. In: XXXVI Encontro da ANPAD, Rio de Janeiro. Brasil, 2012.

NORMAN, M; STOCKER, B. Data Envelopment Analysis the Assessment of Performance. Chichester, England: John Wiley \& Sons, 1991.

PESSANHA, J. F. M. et al. Avaliação dos Custos Operacionais Eficientes das Empresas de Transmissão do Setor Elétrico Brasileiro: uma proposta de adaptação do modelo DEA adotado pela ANEEL,òPesquisa Operacional, Rio de Janeiro, v. 30, pp. 521-545, 2010.

PINDYCK, R. S.; RUBINFELD, D. L. Microeconomia. São Paulo: Makron Books, 1994. 968p.

PINTO JÚNIOR, H. Q. et al. Economia da Energia: fundamentos econômicos, evolução histórica, e organização industrial. Rio de Janeiro. Elsevier, 2007. 343p.

PINTO JÚNIOR, H. Q.; FIANI, R. Regulação econômica. In: KUPFER, D. e HASENCLEVER, L. (Coord.). Economia Industrial: fundamentos teóricos e práticas no Brasil. Rio de Janeiro. Elsevier, 2013. cap. 23, p. 299-312.

PIRES, J. C. L. Desafios da Reestruturação do Setor Elétrico Brasileiro. In: Textos para Discussão BNDES, Rio de Janeiro, n. 76, 2000, 45p.

POSSAS, M. L. et al. Regulação da Concorrência nos Setores de Infraestrutura no Brasil: elementos para um quadro conceitual. In: Infra-estrutura e perspectivas de reorganização ï regulação, F. Rezende e T. B. de Paula, Brasília, 1997, pp. 81-114. 
SANTANA, E. A. de; GOMES, A. A. C. A Reestruturação das Indústrias de Rede: uma avaliação do setor elétrico brasileiro. In: Regulação e gestão competitiva no setor elétrico brasileiro, C. R. Borenstein, Porto Alegre, Sagra-Luzzatto, 1999, pp. 73-93.

SEIFORD, L.M.; ZHU, J. An investigation of returns to scale in data envelopment analysis.The International Journal of Management Science, n. 27, p.1-11, 1999.

SILVA, E. L da. Formação de Preços em Mercados de Energia Elétrica. Porto Alegre: SagraLuzzatto, 2001, 183p.

THANASSOULIS, E. Introduction to the Theory and Application of Data Envelopment Analysis: a foundation text with integrated software, Kluwer Academic Publishers, Boston, Hardbound, EUA, $2001,312 \mathrm{p}$. 
APÊNDICE A: Tabela A1 ï Banco de Dados das Variáveis de Pesquisa

\begin{tabular}{|c|c|c|c|c|c|c|c|}
\hline DMU's & OPEX & Rede & Mercado & $\mathbf{U C}$ & DGC & InvDGC & IASC \\
\hline AESSul2003 & 157015107,47 & 63547,17 & 6925135,03 & 995650 & 0,78 & 1,28 & 60,80 \\
\hline AESSul2004 & 161050449,15 & 65764,47 & 7214026,52 & 1022899 & 0,65 & 1,54 & 63,74 \\
\hline AESSul2005 & 170444674,27 & 67809,57 & 7071159,79 & 1046499 & 0,94 & 1,06 & 66,12 \\
\hline AESSul2006 & 174146204,19 & 70727,87 & 7160008,26 & 1071900 & 0,86 & 1,16 & 65,55 \\
\hline AESSul2007 & 183240409,16 & 72704,37 & 7350552,07 & 1100115 & 1,01 & 0,99 & 69,83 \\
\hline AESSul2008 & 198052980,62 & 74704,76 & 7739746,57 & 1128252 & 1,06 & 0,94 & 67,77 \\
\hline AESSul2009 & 206122961,78 & 76133,22 & 7616460,20 & 1150518 & 1,11 & 0,90 & 69,38 \\
\hline AMPLA2003 & 330777274,11 & 42653,51 & 7344520,89 & 1948127 & 0,98 & 1,02 & 60,25 \\
\hline AMPLA2004 & 370298255,29 & 44113,19 & 7768554,31 & 2036052 & 0,86 & 1,16 & 59,27 \\
\hline AMPLA2005 & 417718740,93 & 45263,78 & 8470064,41 & 2120262 & 0,94 & 1,06 & 59,54 \\
\hline AMPLA2006 & 462115666,66 & 47207,18 & 9055472,68 & 2150376 & 0,76 & 1,32 & 57,90 \\
\hline AMPLA2007 & 475586924,41 & 48708,89 & 9108489,96 & 2218679 & 0,69 & 1,45 & 60,94 \\
\hline AMPLA2008 & 444345606,51 & 50230,90 & 9271567,10 & 2351251 & 0,65 & 1,54 & 57,58 \\
\hline AMPLA2009 & 436532756,10 & 51050,29 & 9506961,35 & 2365558 & 0,96 & 1,04 & 64,03 \\
\hline BANDEIRANTE2003 & 253814373,66 & 25595,57 & 9958394,30 & 1243346 & 0,66 & 1,52 & 68,82 \\
\hline BANDEIRANTE2004 & 281405785,22 & 25657,10 & 12007985,91 & 1272668 & 0,54 & 1,85 & 56,63 \\
\hline BANDEIRANTE2005 & 274193124,26 & 25890,37 & 12043756,29 & 1283446 & 0,69 & 1,45 & 59,97 \\
\hline BANDEIRANTE2006 & 320036160,54 & 26813,69 & 12564274,12 & 1364735 & 0,64 & 1,56 & 62,32 \\
\hline BANDEIRANTE2007 & 297525567,49 & 27017,58 & 12994289,14 & 1401444 & 0,69 & 1,45 & 66,69 \\
\hline BANDEIRANTE2008 & 298475069,87 & 27216,18 & 13456613,56 & 1438804 & 0,81 & 1,23 & 67,22 \\
\hline BANDEIRANTE2009 & 286832273,15 & 27496,38 & 12536237,22 & 1482518 & 0,91 & 1,10 & 69,67 \\
\hline CEAL2003 & 125984952,21 & 23420,06 & 1910847,33 & 635941 & 1,01 & 0,99 & 67,25 \\
\hline CEAL2004 & 141117050,03 & 24728,47 & 1946967,85 & 657908 & 0,99 & 1,01 & 54,89 \\
\hline CEAL2005 & 147696385,93 & 25933,04 & 2120995,88 & 696124 & 0,97 & 1,03 & 56,45 \\
\hline CEAL2006 & 165515275,19 & 26916,70 & 2205426,61 & 733731 & 0,92 & 1,09 & 62,24 \\
\hline CEAL2007 & 183407030,77 & 27863,88 & 2305792,81 & 771369 & 0,9 & 1,11 & 56,15 \\
\hline CEAL2008 & 179156036,14 & 30214,50 & 2432251,49 & 804967 & 0,84 & 1,19 & 63,08 \\
\hline CEAL2009 & 221152028,06 & 32079,00 & 2453674,24 & 831711 & 0,93 & 1,08 & 69,45 \\
\hline CEB2003 & 291208047,62 & 14825,06 & 3594518,75 & 663731 & 0,53 & 1,89 & 62,55 \\
\hline CEB2004 & 294488153,89 & 15436,55 & 3835923,30 & 701977 & 0,61 & 1,64 & 65,80 \\
\hline CEB2005 & 238229110,04 & 15510,18 & 4106409,31 & 730385 & 0,54 & 1,85 & 55,47 \\
\hline CEB2006 & 255538057,60 & 15812,07 & 4303206,72 & 747399 & 0,65 & 1,54 & 61,42 \\
\hline CEB2007 & 242920882,01 & 16001,38 & 4630223,00 & 766497 & 0,83 & 1,20 & 63,13 \\
\hline CEB2008 & 204722459,43 & 16141,76 & 4917793,73 & 794227 & 0,94 & 1,06 & 61,14 \\
\hline CEB2009 & 221978914,57 & 17064,54 & 5210862,75 & 826730 & 1,00 & 1,00 & 70,33 \\
\hline CEEE2003 & 303622886,73 & 45335,73 & 6170515,56 & 1282035 & 0,87 & 1,15 & 63,22 \\
\hline CEEE2004 & 310007724,71 & 49856,11 & 6333767,57 & 1307291 & 0,79 & 1,27 & 62,45 \\
\hline CEEE2005 & 317508776,74 & 54076,74 & 6564007,65 & 1330490 & 0,92 & 1,09 & 66,88 \\
\hline CEEE2006 & 310952455,13 & 58320,37 & 6713070,58 & 1355105 & 1,12 & 0,89 & 67,49 \\
\hline CEEE2007 & 328836937,21 & 62545,43 & 7079139,49 & 1383114 & 1,17 & 0,85 & 71,77 \\
\hline CEEE2008 & 324673495,82 & 66713,96 & 7312179,84 & 1410821 & 1,11 & 0,90 & 61,65 \\
\hline CEEE2009 & 385990997,10 & 71892,26 & 7277929,22 & 1438072 & 1,14 & 0,88 & 69,43 \\
\hline
\end{tabular}

Continua... 
... Continuação

Tabela A1

\begin{tabular}{|c|c|c|c|c|c|c|c|}
\hline DMU's & OPEX & Rede & Mercado & $\mathbf{U C}$ & DGC & InvDGC & IASC \\
\hline CELESC2003 & 569879223,45 & 94610,19 & 14317644,56 & 1958232 & 0,88 & 1,14 & 65,22 \\
\hline CELESC2004 & 605494252,96 & 102761,17 & 14355951,77 & 1972461 & 0,81 & 1,23 & 64,05 \\
\hline CELESC2005 & 602315246,04 & 110929,14 & 15128878,06 & 2061637 & 0,67 & 1,49 & 61,14 \\
\hline CELESC2006 & 712158152,72 & 119115,12 & 15849323,20 & 2079770 & 0,68 & 1,47 & 58,60 \\
\hline CELESC2007 & 756184574,27 & 127346,10 & 17130667,29 & 2148092 & 0,76 & 1,32 & 72,25 \\
\hline CELESC2008 & 744858775,30 & 135528,07 & 17797188,54 & 2207083 & 0,71 & 1,41 & 63,71 \\
\hline CELESC2009 & 721455273,94 & 144896,32 & 18105811,33 & 2237127 & 0,66 & 1,52 & 75,98 \\
\hline CELG2003 & 408293811,99 & 153779,54 & 7167974,85 & 1795060 & 0,86 & 1,16 & 62,47 \\
\hline CELG2004 & 517886510,47 & 168190,89 & 7237738,01 & 1852694 & 0,89 & 1,12 & 52,93 \\
\hline CELG2005 & 641922398,88 & 173433,65 & 7573657,31 & 1915502 & 1,06 & 0,94 & 57,73 \\
\hline CELG2006 & 773112531,65 & 178218,10 & 7861068,40 & 1977910 & 0,91 & 1,10 & 57,99 \\
\hline CELG2007 & 736354226,62 & 184006,69 & 8626988,05 & 2048265 & 1,01 & 0,99 & 62,38 \\
\hline CELG2008 & 655696683,27 & 197271,40 & 9013857,74 & 2133452 & 1,05 & 0,94 & 60,51 \\
\hline CELG2009 & 691472253,23 & 199494,10 & 9344290,61 & 2213198 & 1,12 & 0,89 & 61,36 \\
\hline CELPA2003 & 302366488,07 & 35882,20 & 4183195,65 & 1183353 & 0,86 & 1,16 & 53,97 \\
\hline CELPA2004 & 255012401,93 & 37652,21 & 4439698,40 & 1262644 & 0,84 & 1,19 & 61,13 \\
\hline CELPA2005 & 281752588,14 & 41160,98 & 4739803,41 & 1314656 & 0,95 & 1,05 & 51,75 \\
\hline CELPA2006 & 329912021,45 & 44097,68 & 4931037,71 & 1392942 & 1,15 & 0,87 & 50,27 \\
\hline CELPA2007 & 355686347,25 & 61716,86 & 5334125,34 & 1498159 & 1,61 & 0,62 & 56,93 \\
\hline CELPA2008 & 337057121,49 & 81759,38 & 5694588,31 & 1550651 & 1,97 & 0,51 & 42,03 \\
\hline CELPA2009 & 431929511,47 & 92616,60 & 5734325,47 & 1666664 & 2,15 & 0,47 & 50,89 \\
\hline CELPE2003 & 325952299,11 & 97211,67 & 7573230,47 & 2335152 & 0,36 & 2,78 & 65,39 \\
\hline CELPE2004 & 317498423,85 & 100005,02 & 7392865,55 & 2364115 & 0,47 & 2,13 & 60,95 \\
\hline CELPE2005 & 335839264,45 & 104034,14 & 8261632,70 & 2444743 & 0,43 & 2,33 & 55,33 \\
\hline CELPE2006 & 386762099,21 & 109806,65 & 8629157,06 & 2539830 & 0,49 & 2,04 & 61,46 \\
\hline CELPE2007 & 386726940,20 & 114774,26 & 9125768,74 & 2678068 & 0,5 & 2,00 & 61,67 \\
\hline CELPE2008 & 340768491,76 & 118391,97 & 9581446,41 & 2818524 & 0,53 & 1,89 & 65,30 \\
\hline CELPE2009 & 350651684,28 & 120427,84 & 10001560,01 & 2994259 & 0,58 & 1,72 & 64,25 \\
\hline CELTINS2003 & 90897763,06 & 27371,00 & 794465,25 & 281523 & 0,79 & 1,27 & 65,28 \\
\hline CELTINS2004 & 103952300,20 & 33030,90 & 882697,60 & 298782 & 0,76 & 1,32 & 66,69 \\
\hline CELTINS2005 & 97114126,82 & 37478,43 & 933619,78 & 316667 & 0,69 & 1,45 & 56,30 \\
\hline CELTINS2006 & 116479401,01 & 42356,82 & 966762,25 & 344989 & 0,88 & 1,14 & 51,88 \\
\hline CELTINS2007 & 131176957,47 & 53763,43 & 1069374,28 & 372548 & 0,94 & 1,06 & 57,76 \\
\hline CELTINS2008 & 133049903,49 & 58889,24 & 1149060,73 & 393215 & 1,04 & 0,96 & 56,88 \\
\hline CELTINS2009 & 127969357,67 & 63436,47 & 1232500,69 & 417952 & 1,28 & 0,78 & 63,37 \\
\hline CEMAR2003 & 191744043,10 & 44357,30 & 2507534,01 & 1119136 & 0,63 & 1,59 & 56,21 \\
\hline CEMAR2004 & 188895187,93 & 52640,26 & 2585225,07 & 1164576 & 0,68 & 1,47 & 48,68 \\
\hline CEMAR2005 & 162966535,67 & 60279,09 & 2783687,45 & 1254413 & 0,69 & 1,45 & 48,52 \\
\hline CEMAR2006 & 157905992,76 & 63112,77 & 2893109,42 & 1348912 & 0,61 & 1,64 & 45,67 \\
\hline CEMAR2007 & 156910502,99 & 74093,66 & 3221270,72 & 1437832 & 0,5 & 2,00 & 50,53 \\
\hline CEMAR2008 & 178373848,39 & 79947,10 & 3351862,89 & 1535236 & 0,5 & 2,00 & 48,08 \\
\hline CEMAR2009 & 193088945,94 & 89929,45 & 3571717,73 & 1687939 & 0,51 & 1,96 & 68,91 \\
\hline
\end{tabular}

Continua... 
... Continuação

Tabela A1

\begin{tabular}{|c|c|c|c|c|c|c|c|}
\hline DMU's & OPEX & Rede & Mercado & $\mathbf{U C}$ & DGC & InvDGC & IASC \\
\hline CEMAT2003 & 225382950,86 & 40550,01 & 3665052,90 & 706456 & 0,52 & 1,92 & 60,71 \\
\hline СЕМАТ2004 & 255726431,37 & 43982,11 & 4052551,93 & 750402 & 0,64 & 1,56 & 58,68 \\
\hline СЕMAT2005 & 223000879,15 & 60774,82 & 4330854,96 & 791593 & 0,64 & 1,56 & 54,49 \\
\hline CEMAT2006 & 256522274,57 & 67135,51 & 4363421,40 & 827675 & 0,69 & 1,45 & 57,95 \\
\hline CEMAT2007 & 262767921,55 & 78206,30 & 4844085,39 & 875350 & 0,73 & 1,37 & 66,69 \\
\hline CEMAT2008 & 257691582,06 & 93831,45 & 5257494,57 & 940021 & 0,74 & 1,35 & 51,77 \\
\hline CEMAT2009 & 286211049,75 & 106111,71 & 5570386,63 & 992365 & 0,82 & 1,22 & 65,60 \\
\hline CEMIG2003 & 1319752852,39 & 373893,90 & 35883166,74 & 5744213 & 0,75 & 1,33 & 66,01 \\
\hline CEMIG2004 & 1419901832,30 & 382025,60 & 39148775,49 & 5874993 & 0,71 & 1,41 & 60,92 \\
\hline CEMIG2005 & 1498763149,60 & 393937,70 & 34719145,30 & 5999467 & 0,77 & 1,30 & 63,39 \\
\hline CEMIG2006 & 1660666330,68 & 409847,12 & 36622858,71 & 6240029 & 0,8 & 1,25 & 68,03 \\
\hline CEMIG2007 & 1774784778,45 & 433857,80 & 38125555,59 & 6439993 & 0,81 & 1,23 & 71,63 \\
\hline CEMIG2008 & 1699703652,50 & 455439,67 & 39453498,69 & 6690189 & 0,85 & 1,18 & 69,68 \\
\hline CEMIG2009 & 1682334644,33 & 460219,00 & 37476802,08 & 6832546 & 0,88 & 1,14 & 68,14 \\
\hline CEPISA2003 & 123114268,27 & 34109,10 & 1451469,46 & 667824 & 1,22 & 0,82 & 54,81 \\
\hline CEPISA2004 & 138621245,54 & 34274,00 & 1492129,28 & 695555 & 1,51 & 0,66 & 47,04 \\
\hline CEPISA2005 & 160922797,95 & 35827,86 & 1585360,39 & 728840 & 1,58 & 0,63 & 47,76 \\
\hline CEPISA2006 & 168413837,10 & 41085,30 & 1605507,09 & 768532 & 1,48 & 0,68 & 45,58 \\
\hline CEPISA2007 & 171920463,30 & 43465,30 & 1738696,43 & 812268 & 1,36 & 0,74 & 44,26 \\
\hline CEPISA2008 & 179260048,99 & 46959,65 & 1831085,28 & 848763 & 1,52 & 0,66 & 50,04 \\
\hline CEPISA2009 & 205474266,13 & 48288,15 & 1894081,72 & 892390 & 1,39 & 0,72 & 58,20 \\
\hline COELBA2003 & 452879836,51 & 128742,31 & 9794555,86 & 3342652 & 0,5 & 2,00 & 63,73 \\
\hline COELBA2004 & 437101457,14 & 143245,61 & 10701576,64 & 3459314 & 0,47 & 2,13 & 59,96 \\
\hline COELBA2005 & 420384684,90 & 153188,22 & 11539707,86 & 3652987 & 0,49 & 2,04 & 60,31 \\
\hline COELBA2006 & 469289482,69 & 169646,32 & 12080484,26 & 3913780 & 0,46 & 2,17 & 57,37 \\
\hline COELBA2007 & 478376238,17 & 187114,20 & 12828799,55 & 4174569 & 0,47 & 2,13 & 57,60 \\
\hline COELBA2008 & 418981222,05 & 201862,31 & 13684919,24 & 4407561 & 0,46 & 2,17 & 71,35 \\
\hline COELBA2009 & 436436013,73 & 215001,47 & 14286757,00 & 4622046 & 0,54 & 1,85 & 67,44 \\
\hline COELCE2003 & 279036160,14 & 78278,46 & 5836870,65 & 2123849 & 0,56 & 1,79 & 59,81 \\
\hline COELCE2004 & 270114374,90 & 85310,74 & 6280695,93 & 2230282 & 0,53 & 1,89 & 56,01 \\
\hline COELCE2005 & 287444169,66 & 94627,00 & 6747347,94 & 2325686 & 0,47 & 2,13 & 56,36 \\
\hline COELCE2006 & 307266295,06 & 95997,00 & 6898065,40 & 2416184 & 0,44 & 2,27 & 56,30 \\
\hline COELCE2007 & 335335958,60 & 106140,00 & 7362090,58 & 2490241 & 0,38 & 2,63 & 66,89 \\
\hline COELCE2008 & 331646406,53 & 114973,78 & 7676947,87 & 2683269 & 0,37 & 2,70 & 56,51 \\
\hline COELCE2009 & 316166875,97 & 120299,97 & 7929212,21 & 2744830 & 0,38 & 2,63 & 78,98 \\
\hline COPEL2003 & 650588873,09 & 201064,70 & 17705374,07 & 3095491 & 1,13 & 0,88 & 68,85 \\
\hline COPEL2004 & 719446562,50 & 205738,74 & 19382602,10 & 3180079 & 0,98 & 1,02 & 61,51 \\
\hline COPEL2005 & 782854616,91 & 209302,59 & 20151637,93 & 3256589 & 0,92 & 1,09 & 74,44 \\
\hline COPEL2006 & 819373557,37 & 212515,67 & 20737581,52 & 3345347 & 1 & 1,00 & 69,96 \\
\hline COPEL2007 & 856222030,42 & 216863,10 & 22069891,71 & 3437093 & 0,96 & 1,04 & 70,87 \\
\hline COPEL2008 & 878914610,52 & 220791,38 & 23266889,04 & 3523573 & 0,88 & 1,14 & 65,50 \\
\hline COPEL2009 & 1018866491,07 & 224817,29 & 23525040,18 & 3628209 & 0,87 & 1,15 & 69,89 \\
\hline
\end{tabular}

Continua... 
... Continuação

Tabela A1

\begin{tabular}{|c|c|c|c|c|c|c|c|}
\hline DMU's & OPEX & Rede & Mercado & $\mathbf{U C}$ & DGC & InvDGC & IASC \\
\hline COSERN2003 & 121510494,53 & 32470,81 & 3016566,36 & 789339 & 0,44 & 2,27 & 70,33 \\
\hline COSERN2004 & 114240365,23 & 32803,11 & 3211705,86 & 816699 & 0,53 & 1,89 & 60,56 \\
\hline COSERN2005 & 114190502,83 & 34053,26 & 3509180,54 & 857662 & 0,55 & 1,82 & 61,85 \\
\hline COSERN2006 & 136600393,09 & 37049,37 & 3736182,72 & 913486 & 0,52 & 1,92 & 61,42 \\
\hline COSERN2007 & 136136809,75 & 40066,22 & 3991726,30 & 963493 & 0,56 & 1,79 & 71,37 \\
\hline COSERN2008 & 118751243,62 & 41722,22 & 4080880,28 & 1006818 & 0,55 & 1,82 & 70,74 \\
\hline COSERN2009 & 123013652,98 & 43272,17 & 4130635,61 & 1075590 & 0,59 & 1,69 & 66,19 \\
\hline CPFLPaulista2003 & 473263718,96 & 77739,40 & 19638882,82 & 3027991 & 0,56 & 1,79 & 69,35 \\
\hline CPFLPaulista2004 & 455444591,19 & 80013,23 & 21025223,27 & 3093497 & 0,55 & 1,82 & 59,69 \\
\hline CPFLPaulista2005 & 486284196,83 & 81255,60 & 22196144,94 & 3172500 & 0,62 & 1,61 & 65,35 \\
\hline CPFLPaulista2006 & 471679068,74 & 83769,52 & 23065652,97 & 3250301 & 0,66 & 1,52 & 66,55 \\
\hline CPFLPaulista2007 & 500193755,45 & 86816,78 & 24419598,70 & 3335015 & 0,72 & 1,39 & 62,85 \\
\hline CPFLPaulista2008 & 486380022,69 & 89019,73 & 25287667,34 & 3427898 & 0,71 & 1,41 & 73,76 \\
\hline CPFLPaulista2009 & 497290781,90 & 89879,00 & 25267579,26 & 3502793 & 0,75 & 1,33 & 68,15 \\
\hline CPFLPiratininga2003 & 202995724,40 & 20007,95 & 10507415,14 & 1151780 & 0,6 & 1,67 & 66,99 \\
\hline CPFLPiratininga2004 & 202756242,68 & 20506,08 & 12694450,61 & 1193663 & 0,63 & 1,59 & 55,79 \\
\hline CPFLPiratininga2005 & 195330179,02 & 20676,88 & 12888798,42 & 1216243 & 0,71 & 1,41 & 68,45 \\
\hline CPFLPiratininga2006 & 196126531,20 & 21096,02 & 13215702,58 & 1250094 & 0,64 & 1,56 & 63,61 \\
\hline CPFLPiratininga2007 & 214482135,94 & 21705,49 & 12782545,35 & 1286491 & 0,67 & 1,49 & 70,63 \\
\hline CPFLPiratininga2008 & 194183405,68 & 21712,91 & 13295003,96 & 1328159 & 0,65 & 1,54 & 66,52 \\
\hline CPFLPiratininga2009 & 195789961,03 & 22235,63 & 13013378,29 & 1367488 & 1,01 & 0,99 & 69,08 \\
\hline ELEKTRO2003 & 364192348,83 & 95306,45 & 10670299,83 & 1819607 & 0,8 & 1,25 & 66,33 \\
\hline ELEKTRO2004 & 359348119,48 & 96773,45 & 11725173,09 & 1862598 & 0,79 & 1,27 & 57,91 \\
\hline ELEKTRO2005 & 397201045,28 & 98699,95 & 11804866,58 & 1904639 & 0,81 & 1,23 & 65,68 \\
\hline ELEKTRO2006 & 430692725,51 & 101211,22 & 12248622,55 & 1954422 & 0,79 & 1,27 & 63,60 \\
\hline ELEKTRO2007 & 424867304,51 & 103791,15 & 12918860,73 & 2005109 & 0,74 & 1,35 & 73,24 \\
\hline ELEKTRO2008 & 411222070,42 & 105825,19 & 13455777,96 & 2067357 & 0,7 & 1,43 & 72,67 \\
\hline ELEKTRO2009 & 414602018,28 & 107115,75 & 13398558,26 & 2123670 & 0,88 & 1,14 & 70,21 \\
\hline ELETROPAULO2003 & 1310777756,64 & 39392,96 & 33308269,94 & 5056795 & 0,7 & 1,43 & 60,01 \\
\hline ELETROPAULO2004 & 1055561325,44 & 41778,19 & 35117392,59 & 5147420 & 0,7 & 1,43 & 57,33 \\
\hline ELETROPAULO2005 & 1088800746,94 & 42333,70 & 35916507,56 & 5300106 & 0,73 & 1,37 & 58,42 \\
\hline ELETROPAULO2006 & 1168654491,73 & 44058,65 & 37183977,05 & 5468760 & 0,64 & 1,56 & 64,70 \\
\hline ELETROPAULO2007 & 1139787894,34 & 44529,97 & 38845837,62 & 5651915 & 0,71 & 1,41 & 65,52 \\
\hline ELETROPAULO2008 & 1044552699,01 & 44913,37 & 40259597,21 & 5830961 & 0,73 & 1,37 & 65,10 \\
\hline ELETROPAULO2009 & 1249143612,84 & 45212,99 & 39922709,71 & 5987873 & 1,24 & 0,81 & 71,51 \\
\hline EMG2003 & 58286371,56 & 20038,12 & 989514,32 & 297962 & 0,68 & 1,47 & 67,43 \\
\hline EMG2004 & 70203411,17 & 20333,18 & 1030711,25 & 306258 & 0,71 & 1,41 & 63,00 \\
\hline EMG2005 & 75874746,02 & 20683,71 & 1066376,72 & 316478 & 0,69 & 1,45 & 61,96 \\
\hline EMG2006 & 67159304,21 & 21608,39 & 1140168,77 & 331403 & 0,77 & 1,30 & 56,22 \\
\hline EMG2007 & 72810547,80 & 22958,01 & 1200142,82 & 341790 & 0,88 & 1,14 & 71,73 \\
\hline EMG2008 & 69533658,62 & 24291,49 & 1258560,31 & 359084 & 1,13 & 0,88 & 74,88 \\
\hline EMG2009 & 74652712,68 & 25338,27 & 1295719,67 & 371253 & 1,28 & 0,78 & 68,15 \\
\hline
\end{tabular}

Continua... 
... Continuação

Tabela A1

\begin{tabular}{|c|c|c|c|c|c|c|c|}
\hline DMU's & OPEX & Rede & Mercado & $\mathbf{U C}$ & DGC & InvDGC & IASC \\
\hline ENERSUL2003 & 136694258,30 & 38254,90 & 2821995,54 & 620344 & 0,62 & 1,61 & 61,92 \\
\hline ENERSUL2004 & 143887689,21 & 42494,90 & 3014684,01 & 645904 & 0,52 & 1,92 & 55,46 \\
\hline ENERSUL2005 & 167343092,99 & 47453,12 & 3051935,80 & 664182 & 0,62 & 1,61 & 57,69 \\
\hline ENERSUL2006 & 214079932,47 & 54076,19 & 3068649,53 & 695132 & 0,76 & 1,32 & 55,43 \\
\hline ENERSUL2007 & 222750745,88 & 66680,52 & 3204095,39 & 716958 & 0,72 & 1,39 & 61,47 \\
\hline ENERSUL2008 & 204320820,17 & 70894,32 & 3349998,33 & 748000 & 0,68 & 1,47 & 53,61 \\
\hline ENERSUL2009 & 202460582,59 & 74503,98 & 3441581,44 & 784816 & 0,75 & 1,33 & 61,09 \\
\hline EPB2003 & 99557723,83 & 49964,65 & 2278965,19 & 831609 & 0,41 & 2,44 & 57,21 \\
\hline EPB2004 & 115934755,60 & 52299,96 & 2343209,00 & 863794 & 0,71 & 1,41 & 58,70 \\
\hline EPB2005 & 117533027,72 & 55484,09 & 2559908,59 & 884829 & 0,91 & 1,10 & 60,81 \\
\hline EPB2006 & 123309090,82 & 56359,89 & 2663265,13 & 926778 & 0,96 & 1,04 & 59,28 \\
\hline EPB2007 & 158040221,94 & 59442,49 & 2804844,10 & 970499 & 0,78 & 1,28 & 66,50 \\
\hline EPB2008 & 159581380,52 & 60640,49 & 2947329,20 & 1016081 & 0,74 & 1,35 & 61,58 \\
\hline EPB2009 & 169707732,51 & 65373,65 & 3061728,03 & 1059575 & 1,02 & 0,98 & 64,12 \\
\hline ESCELSA2003 & 175023058,94 & 46079,74 & 6302577,73 & 972420 & 0,76 & 1,32 & 64,24 \\
\hline ESCELSA2004 & 176056217,70 & 47460,01 & 7133669,77 & 988621 & 0,88 & 1,14 & 57,88 \\
\hline ESCELSA2005 & 197620014,30 & 50112,67 & 7633260,82 & 1039414 & 0,83 & 1,20 & 55,56 \\
\hline ESCELSA2006 & 242203382,09 & 51827,20 & 8041042,40 & 1064746 & 0,61 & 1,64 & 60,27 \\
\hline ESCELSA2007 & 256048340,08 & 53363,56 & 8488323,04 & 1100902 & 0,81 & 1,23 & 67,31 \\
\hline ESCELSA2008 & 228157012,38 & 55289,96 & 8748326,93 & 1150869 & 0,77 & 1,30 & 63,06 \\
\hline ESCELSA2009 & 241433335,36 & 56959,90 & 7897969,48 & 1185432 & 0,85 & 1,18 & 60,97 \\
\hline ESE2003 & 75559348,18 & 14940,70 & 1990917,86 & 434378 & 0,63 & 1,59 & 68,74 \\
\hline ESE2004 & 76256924,06 & 15326,43 & 2118499,05 & 451835 & 0,59 & 1,69 & 55,06 \\
\hline ESE2005 & 74428507,93 & 16656,70 & 2270398,53 & 467690 & 0,57 & 1,75 & 60,97 \\
\hline ESE2006 & 81112648,41 & 17615,37 & 2401495,35 & 490338 & 0,6 & 1,67 & 65,03 \\
\hline ESE2007 & 95269565,65 & 19889,09 & 2442043,51 & 517337 & 0,71 & 1,41 & 62,79 \\
\hline ESE2008 & 101193814,24 & 21587,92 & 2527853,56 & 546304 & 0,92 & 1,09 & 63,54 \\
\hline ESE2009 & 99040087,92 & 23851,00 & 2671865,16 & 570152 & 0,78 & 1,28 & 55,58 \\
\hline LIGHT2003 & 663293636,63 & 55014,57 & 18079337,76 & 3368831 & 0,71 & 1,41 & 60,78 \\
\hline LIGHT2004 & 623452310,87 & 55671,80 & 23326824,24 & 3434928 & 0,69 & 1,45 & 58,99 \\
\hline LIGHT2005 & 599327194,93 & 55926,80 & 25000685,41 & 3446492 & 0,79 & 1,27 & 60,39 \\
\hline LIGHT2006 & 651397354,16 & 56409,00 & 22837838,82 & 3458097 & 0,69 & 1,45 & 66,97 \\
\hline LIGHT2007 & 703673559,62 & 56923,00 & 23355598,44 & 3483322 & 0,76 & 1,32 & 66,88 \\
\hline LIGHT2008 & 604034676,24 & 57588,00 & 23692046,99 & 3517004 & 0,87 & 1,15 & 56,20 \\
\hline LIGHT2009 & 557206112,45 & 58074,00 & 22902551,88 & 3640182 & 1,06 & 0,94 & 64,22 \\
\hline RGE2003 & 155149228,44 & 75688,42 & 6372427,53 & 1052275 & 0,85 & 1,18 & 65,54 \\
\hline RGE2004 & 197719189,70 & 76366,92 & 6768044,07 & 1072280 & 0,86 & 1,16 & 65,17 \\
\hline RGE2005 & 179415228,48 & 78154,92 & 6873055,86 & 1094642 & 1,01 & 0,99 & 66,75 \\
\hline RGE2006 & 189584358,35 & 80665,46 & 7074411,91 & 1122842 & 0,82 & 1,22 & 66,74 \\
\hline RGE2007 & 184142085,05 & 82664,10 & 7650265,24 & 1157865 & 0,86 & 1,16 & 70,75 \\
\hline RGE2008 & 187400571,11 & 83982,52 & 8066797,19 & 1192867 & 0,76 & 1,32 & 65,97 \\
\hline RGE2009 & 186357414,62 & 84996,52 & 7993102,64 & 1226079 & 0,75 & 1,33 & 71,12 \\
\hline
\end{tabular}

Fonte: Compilação Própria. (Banco de Dados ANEEL). 